\title{
PROPOSTA DE UM CHECK LIST PARA UTILIZAÇÃO NO PROCESSO DE ANÁLISE DE REQUERIMENTOS DO MÓDULO DE SUPRIMENTOS DE SOFTWARE ERP
}

\section{PROPOSAL FOR A CHECK LIST FOR USE IN THE PROCESS OF ANALYZING REQUIREMENTS SUPPLY MODULE ERP SOFTWARE}

\author{
Zaida Cristiane dos Reis ${ }^{1}$, Tiago da Rosa ${ }^{2}$ e Gabriel Sperandio Milan ${ }^{3}$ \\ ${ }^{1}$ Universidade de Caxias do Sul - UCS - Caxias do Sul - RS - Brasil \\ zcreis@gmail.com \\ ${ }^{2}$ Universidade de Caxias do Sul - UCS - Caxias do Sul - RS - Brasil \\ tiago.rosa@focco.com.br \\ ${ }^{3}$ Universidade de Caxias do Sul - UCS - Caxias do Sul - RS - Brasil \\ gabmilan@terra.com.br
}

\begin{abstract}
Resumo
O objetivo central deste trabalho é propor uma sugestão aplicada a fase de análise de requerimentos do projeto de implementação de um sistema ERP para o módulo de suprimentos. $O$ sucesso da etapa de análise de requerimentos impacta em todas as posteriores do projeto, influindo principalmente em cronogramas e custos do projeto. $O$ desafio é fazer com que os implementadores deste sistema possam com este check list descobrir todas as atividades, tarefas e processos existentes na área de suprimentos e logística das empresas. Para isso foi realizado um estudo de caso em uma empresa de sistemas de gestão empresarial, analisando dados de diversas fontes sobre seus projetos e verificando quais os tópicos principais de ajustes e investimentos dos projetos. São demonstradas também quais as fases do projeto de implementação de tal sistema e o seu fluxo. O questionário proposto é feito de acordo com as subdivisões do módulo de suprimentos visando obter o máximo de informações da empresa que irá trocar de sistema. Ao final do trabalho apresentam-se os resultados desejados com a proposta.
\end{abstract}

Palavras-chave: análise de requerimentos; sistema; suprimentos.

\section{Introdução}

$\mathrm{Na}$ busca de resultados rápidos em virtude de um mercado altamente exigente as organizações procuram desenvolver e se adaptar rapidamente as mudanças e exigências dos seus clientes, fornecedores, funcionários e órgãos públicos. Estas fazem com que a empresa analise suas habilidades e conhecimentos para verificar como atender tais demandas ou necessidades.

Observa-se que na grande maioria dos negócios, o sucesso dos projetos depende das constantes melhorias contínuas em todas as suas etapas, sempre levando em conta todos os aspectos que se referem ao conhecimento de desenvolvimentos passados ao qual devem ser avaliados 
resultados obtidos e desejados, analisando quais pontos que trouxeram resultados positivos e negativos. Os pontos considerados como insucesso devem ser trabalhados arduamente para se obter resultados melhores no futuro.

Este artigo trata especificamente do ajuste de uma das etapas do projeto de implementação de um ERP. Visando justamente melhorar a fase de análise de requerimentos do módulo de suprimentos de um sistema ERP para que em todos os desenvolvimentos sejam detectadas as melhores informações sobre a empresa que irá trocar de sistema. Proporcionar também ao organizador do processo a melhor maneira de preparar os dados para as futuras definições para implementar o sistema ou detectar quais situações não contemplam e necessitam de uma melhor customização.

A proposta tem em vista não somente sugerir uma melhoria na etapa inicial do sistema analisado, mas quer fazer com que o conhecimento tácito existente na empresa se transforme em explícito ficando armazenado no ERP e por consequiência seja uma implementação com sucesso, agregando valor nas suas operações e seus processos.

\section{Referencial Teórico}

\subsection{Capital Intelectual}

Segundo Antunes e Martins (2002), Capital Intelectual - CI são todos os ativos intangíveis de uma organização, a marca, as competências das pessoas, a expertise dos empregados, as licenças, as patentes e os processos organizacionais determinantes para a criação de valor. O contexto de CI iniciou a se desenvolver em 1959, quando tiveram o início o desenvolvimento e debate sobre uma nova perspectiva estratégica do mundo empresarial. Essa visão foi caracterizada pelo fator de vantagem competitiva, de maneira que as organizações começaram a sentir que esse assunto é de alta importância, gerando diferencial no atual mercado global de competição.

Drucker (2000) afirma que nessa sociedade, o conhecimento é o recurso primário para os indivíduos e para a economia como um todo. A terra, o trabalho e o capital, os tradicionais fatores de produção para os economistas, não desapareceram, mas se tornaram secundários. Eles podem ser obtidos, e porque não dizer até sem grandes esforços, desde que haja um conhecimento especializado. Ao mesmo tempo, entretanto, o conhecimento especializado por si só não produz nada. Ele pode se tornar produtivo quando for integrado a uma tarefa. E esta é uma razão porque a sociedade do conhecimento é também uma sociedade das organizações: a finalidade e função de toda a organização, comercial ou não, é a integração dos conhecimentos especializados com tarefas comuns. 
É inegável a influência que o conhecimento tem sobre o mercado, e de como as empresas e produtos são atingidos por esta variável. Stewart (1998) afirma que hoje "o conhecimento tornou-se a principal matéria-prima e resultado da atividade econômica das empresas, a inteligência organizacional deixou de ser um papel coadjuvante, para assumir um papel principal”.

Davenport (2001) coloca que conhecimento é informação valiosa da mente humana, inclui reflexão síntese e contexto, é de difícil estruturação, freqüentemente tácito e suas transferências são complexas. Davenport (2001) ainda explica que conhecimento é a informação mais valiosa e, conseqüentemente, mais difícil de gerenciar. Isso ocorre porque alguém deu à informação um contexto, um significado, uma interpretação, refletiu sobre o conhecimento, acrescentou a ela sua própria sabedoria, considerou suas implicações mais amplas. Fato de grande relevância hoje nas empresas, pois seus colaboradores absorvem e moldam processos de acordo com o conhecimento existente na empresa para agregar valor as suas atividades.

Segundo Antunes e Martins (2002), o capital intelectual pode ser dividido em quatro categorias:

a) Ativos de Mercado: são os potenciais que a empresa possui em decorrência dos intangíveis que estão relacionados ao mercado, tais como: marca, clientes, lealdade dos clientes, negócios recorrentes e em andamento, canais de distribuição, franquias entre outros;

b) Ativos Humanos: destacam-se os benefícios que o indivíduo pode proporcionar para as organizações por meio da sua expertise, criatividade, conhecimento e habilidade para resolver problemas;

c) Ativos de Propriedade Intelectual: são todos os ativos que necessitam de proteção legal para proporcionar às organizações benefícios tais como: know-how, segredos industriais, copyright, patentes, designs, entre outros;

d) Ativos de Infra-Estrutura: compreendem as tecnologias, as metodologias e os processos empregados, como cultura, sistema de informação, métodos gerenciais, aceitação de risco, banco de dados de clientes, etc.

\subsection{Gestão do Conhecimento}

Surgido por volta dos anos 80, o conceito de Gestão do Conhecimento - GC vem ganhando destaque entre as empresas, como uma estratégia organizacional que possibilita vantagens competitivas, podendo garantir às organizações diferenciação no mercado. O tema recebe atenção, pois, com tecnologia de acesso fácil à grande maioria das empresas, o diferencial passa a ser as pessoas e o conhecimento que estas adquirem ao longo do tempo. Porém, como reter este conhecimento e gerenciá-lo de forma que a empresa possa ter bons resultados? Esta é a principal proposta da GC (GONÇALVES; RODRIGUES, 2008; HOLANDA et al., 2008). 
Amaral et al. (2006) definem a GC como o conjunto de práticas e atividades que se destinam a incentivar e garantir a criação, compartilhamento e disseminação de informações e a troca de experiências, buscando a melhoria contínua das competências das pessoas e o crescimento do conhecimento organizacional. Os autores destacam que o conhecimento, embora difícil de ser medido, é fundamental para o aumento da competência dos funcionários.

Neste sentido, Nonaka e Takeuchi (1997) defendem que o conhecimento deve ser explícito, ou seja, algo formal e sistemático. Ainda, segundo os autores Nonaka e Takeuchi (1997, p. 07): “O conhecimento explícito pode ser expresso em palavras e números, e facilmente comunicado e compartilhado sob a forma de dados brutos, fórmulas científicas, procedimentos codificados ou princípios universais".

Cabe ressaltar que o conhecimento pessoal, adquirido com as ações e experiências, e de complexa mensuração, é identificado como conhecimento tácito. De acordo com Nonaka e Takeuchi (1997), as empresas japonesas consideram o conhecimento explícito como sendo apenas o início de um processo, sendo o restante creditado ao conhecimento tácito, algo dificilmente visível e exprimível. "O conhecimento tácito é altamente pessoal e difícil de formalizar, o que dificulta sua transmissão e compartilhamento com outros" (NONAKA; TAKEUCHI, 1997, p. 07). Sobre este aspecto, Zabot e Silva (2002) destacam que para que o conhecimento possa ser compartilhado dentro de uma organização deve ser convertido de tácito para explícito, e vice-versa.

Sobre este aspecto Morgan e Liker (2008), destacam que a maioria das empresas foca seus esforços no conhecimento explícito, formando bancos de dados volumosos e, devido à complexidade, possuem dificuldade para gerir o conhecimento tácito. Os autores destacam que o conhecimento tácito é complexo, "confuso" e de difícil transferência, seu compartilhamento requer laços complexos entre os participantes, representando relacionamentos mais profundos.

Dyer e Nobeoka (1998) apud Morgan e Liker (2008), consideram o conhecimento tácito como o maior potencial competitivo de uma empresa, mesmo este sendo de difícil aprendizado, gerenciamento e aplicação. Este fator torna de maior complexidade a imitação pelos concorrentes, o que não ocorre com o conhecimento explícito, que é mais fácil de compilar e armazenar.

Como forma de interação social entre o conhecimento tácito e explícito e redução das barreiras da transferência do conhecimento, Nonaka e Takeuchi (1997) propõe a espiral do conhecimento, conforme figura 1 . 


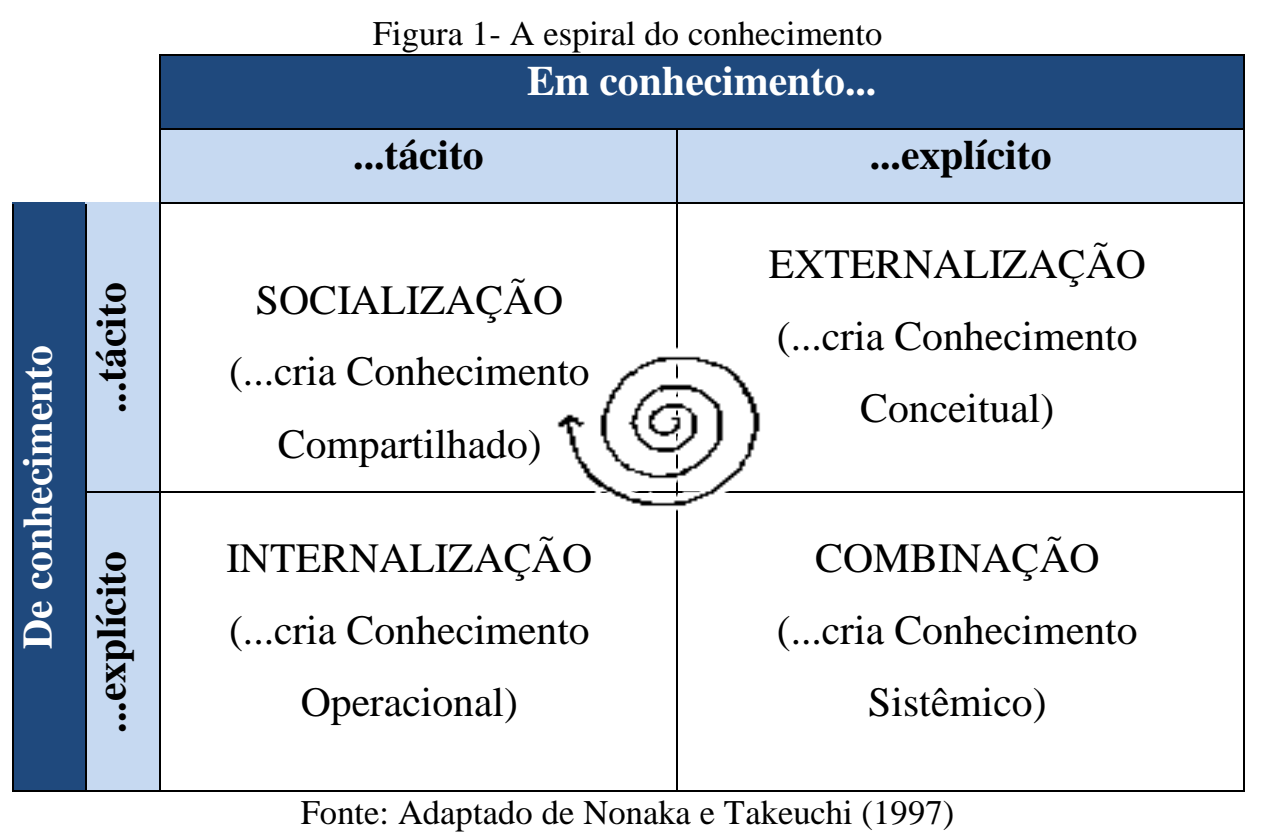

Abaixo, apresenta-se a interpretação da figura 1, pela visão de Nonaka e Takeuchi (1997):

- Socialização (de tácito para tácito): trata-se do "processo de compartilhamento de experiências e, a partir daí, da criação do conhecimento tácito, como modelos mentais ou habilidades técnicas compartilhadas." (NONAKA; TAKEUCHI, 1997, p. 69). Neste sentido uma pessoa compartilha o conhecimento tácito diretamente com a outra, através da observação e imitação das práticas dos outros, como uma troca de experiências;

- Externalização (de tácito para explícito): é um processo de conversão do conhecimento tácito em explícito. Sobre este aspecto, Nonaka e Takeuchi (1997) ressaltam que para converter o conhecimento tácito em explícito de forma eficiente e eficaz, deve ser feito o uso seqüencial da metáfora, analogia e hipóteses, diálogo, reflexão coletiva, e dedução, reflexão e indução. Os autores destacam ainda que este pode ser considerado o principal modo de conversão do conhecimento, pois cria conceitos novos e explícitos para a organização, ou seja, se interpreta o conhecimento tácito e o sistematiza, na forma escrita, vídeos, ou outras formas de armazenamento;

- Combinação (de explícito para explícito): neste modo de compartilhamento, Nonaka e Takeuchi (1997) destacam que as pessoas trocam e combinam conhecimentos através de documentos, reuniões, conversas ao telefone e/ou rede de comunicação computadorizadas. Inclui-se também neste modo a criação do conhecimento que se dá através da educação, dos treinamentos formais nas escolas. Para os autores esta é a combinação de partes distintas de conhecimento explícito, formando um todo novo;

- Internalização (de explícito para tácito): a transformação de explícito para tácito, segundo Nonaka e Takeuchi (1997), se dá através da verbalização e diagramação do conhecimento através de documentos, manuais ou histórias reais. A documentação ajuda os indivíduos a internalizarem suas experiências, aumentando assim o seu conhecimento tácito. "Além disso, 
documentos ou manuais facilitam a transferência do conhecimento explícito para outras pessoas, ajudando-as a vivenciar indiretamente as experiências dos outros" (NONAKA; TAKEUCHI, 1997, p.78).

Na visão de Gonçalves e Rodrigues (2008), os processos de externalização e internalização são as etapas críticas do espiral do conhecimento. Isso se dá, pois, em ambas as fases, existem a necessidade do comprometimento ativo da própria pessoa, caso contrário, não há meios do conhecimento desenvolver-se na organização. Através deste comprometimento, os indivíduos se dispõem a compartilhar aquilo que possuem de mais valioso: o seu conhecimento.

\subsection{Mapas conceituais em GC}

Para Terra (2001), a relação entre a tecnologia e a gestão do conhecimento consiste no uso dos sistemas citados acima para o compartilhamento de informações ou conhecimentos. $\mathrm{O}$ autor, classifica estes sistemas de "compartilhamento" em três modelos: (i) sistemas de publicação e documentação; (ii) mapas de conhecimento; e (iii) sistemas de colaboração (chats, videoconferência, e-mail, etc.).

Os mapas conceituais resultam das pesquisas de Novak e Gowin, citadas por Cañas et al. (2003) sobre o aprendizado humano e da criação do conhecimento. A idéia principal nestes estudos acerca da cognição está associada ao fato de que o aprender acontece a partir da assimilação de novos conceitos.

Se converter o conhecimento tácito em explícito é algo difícil, a idéia fundamental dos mapas conceituais é justamente representar, graficamente, o conhecimento, através de conceitos e ligações, de tal forma que a sua assimilação seja a mais fácil possível.

É importante destacar que um mapa de conhecimento pretende e deve apenas dar a direção de onde está o conhecimento, e não contê-lo em si, ou seja, um mapa de conhecimento deve funcionar como um guia e não um repositório. O processo de criação do mapa consiste em encontrar os conhecimentos importantes dentro da organização e depois publicá-los. O mapa é o meio, não o fim (DAVENPORT; PRUSAK, 1998).

De acordo com Davenport e Prusak (1998), os benefícios na utilização de um mapa de conhecimento podem se destacar como:

- Evitar que erros sejam cometidos pelo recebimento de informações erradas;

- Ganhar agilidade, isto é, evitar gastar tempo procurando um conhecimento (ou a reinvenção da roda);

- Acesso direto à fonte do conhecimento.

Neste sentido, o objetivo de um sistema é fazer da criação dos mapas conceituais um processo simples, possível para qualquer pessoa. Outra característica que se busca está ligada ao 
fato de possibilitar que os mapas sejam criados com a ajuda de outras pessoas, ou seja, tornando-se um processo um trabalho de equipe; o compartilhamento do conhecimento e a colaboração estão presentes na ideologia do software (CAÑAS et al., 2004).

\subsection{Conhecimento e Tecnologia de Informação como diferencial competitivo}

Atualmente as empresas precisam criar, absorver ou desenvolver conhecimentos nos seus diversos setores observa-se que isso acontece por vários motivos, iniciando na competição global entre as empresas, ou ainda nas habilidades básicas em logística, qualidade, tecnologia da informação, entre outros. Identifica-se que muitas habilidades não podem mais ser vistas como diferenciais no mercado e sim como premissas básicas para qualquer negócio.

Spender (2001) na mesma direção descreve que na Era da Informação ou na Era do Trabalho do Conhecimento, que suas possibilidades e restrições estratégicas já não estão baseadas na limitação do capital, na demanda, na capacidade de produção ou acesso a mercados estrangeiros. As restrições comerciais atuais são derivadas, principalmente, da escassez de pessoas disponíveis para levar a empresa à economia globalizada. Não quer dizer que o trabalho das pessoas seja desqualificado, diz respeito aos agentes humanos que podem reunir recursos intangíveis com recursos convencionalmente gerenciados e, assim aumentar o valor para o cliente.

No modelo de busca e uso da informação apresentado por Choo (2003), as necessidades de informação podem ser analisadas em termos de elementos cognitivos, emocionais e situacionais. Pode começar com o indivíduo apresentando uma sensação de intranqüilidade sobre o seu grau e reflexões, até o indivíduo ser capaz de expressá-la na forma narrativa ou de afirmações dispersas.

Engel et al. (2000) abordam critérios e avaliações como sendo características particulares das organizações que são usados no julgamento das alternativas de escolha conforme a sua necessidade. Os critérios avaliativos são expressos de acordo com as características desejadas em uma informação. Nesta etapa, o usuário utilizará as informações desenvolvidas pelas equipes para desenvolver um conjunto de critérios que vão auxiliar a avaliar e comparar as alternativas. Alguns diferenciais mais comuns são: confiabilidade, qualidade, rapidez, entre outros. Quando as opções são comparadas, os usuários começam a levar em consideração a importância e a qualidade da informação.

Spender (2001) ainda coloca que os gerentes atuais estão conscientes de que a extensão, a profundidade e o escopo do conhecimento e das habilidades da empresa impulsionam, crescentemente, suas chances competitivas. Tem consciência de que, do ponto de vista gerencial, há pouca diferença entre capital humano que vai para casa a noite e o que se torna disponível através de alianças estratégicas. Lidar com as incertezas apresentadas pela competição baseada no 
conhecimento exige que as empresas desenvolvam um sentido claro sobre si mesmo, suas forças e fraquezas e habilidades de enfrentar e de gerenciar os riscos de maior dependência de outros.

Neste sentido Nonaka (2000) afirma que numa época em que os mercados se deslocam, as tecnologias proliferam, os concorrentes se multiplicam e os produtos se tornam obsoletos quase que de um dia para o outro, as empresas de sucesso são as que consistentemente criam conhecimento novo, disseminam esse conhecimento amplamente a toda organização e, rapidamente, o incorporam a novas tecnologias e produtos. Essas atividades definem a empresa "criadora de conhecimento", cujo único negócio é a inovação contínua.

Segundo Johnson (2004), a maioria das empresas vem enfrentando dificuldades no desenvolvimento de projetos de gestão do conhecimento, por algumas razões específicas como: os gestores têm dificuldade em identificar quem efetivamente está gerando um desempenho excepcional e como essas forças iriam interagir em outro departamento ou unidade; as pessoas não transferem o conhecimento para outras situações por não terem confiança que o mesmo seja eficaz em uma nova situação; os membros da organização não percebem ou não reconhecem seus pares como especialistas; as pessoas não reconhecem o valor do conhecimento, ou não têm habilidades e experiências necessárias, ou ainda, não usam o conhecimento transferido a ponto de incorporar no seu modo de trabalho; as organizações não dispõem de sistemas e estruturas para capacitar as pessoas, reconhecer e alavancar o conhecimento existente; as pessoas de diferentes unidades não têm histórico positivo de comunicação e colaboração.

\subsection{Modelo conceitual de análise}

A gestão do conhecimento, resumidamente, busca aprimorar e desenvolver novos conceitos, e neste sentido, entende-se a importância da sua interação com as Tecnologias de Informação (TIs).

Ao finalizar o desenvolvimento do referencial teórico, entende-se a necessidade de apresentar os conceitos principais que vão embasar o desenvolvimento deste estudo, assim, no quadro 1, são evidenciados os principais conceitos citados até o momento, juntamente com os respectivos autores que embasam esta literatura, buscando assim, realizar um fechamento deste item.

Observa-se que a abordagem relatada nesse modelo conceitual de análise resgata conceitos significativos que apontam para questões sobre aprender através das experiências, a diferenciação entre conhecimento tácito e explícito, assim como, vantagem competitiva e fatores orientadores e facilitadores de aprendizado. 
Quadro 1 - Modelo conceitual de análise sobre a gestão do conhecimento

\begin{tabular}{|c|c|}
\hline & Autores que embasaram a análise \\
\hline $\begin{array}{c}\text { Capital intelectual como ativo intangível das } \\
\text { organizações. Conhecimento agregando valor as } \\
\text { tarefas. }\end{array}$ & $\begin{array}{l}\text { Antunes e Martins (2002); Drucker (2000); Stewart } \\
\text { (1998). }\end{array}$ \\
\hline $\begin{array}{l}\text { Conhecimento tácito, conhecimento explícito, criação, } \\
\text { compartilhamento transferência e disseminação. }\end{array}$ & $\begin{array}{c}\text { Nonaka e Takeuchi (1997); Davenport (2001); Zabot e } \\
\text { Silva (2002); Amaral et al. (2006); Morgan e Liker } \\
\text { (2008); Gonçalves e Rodrigues (2008). }\end{array}$ \\
\hline Processos de externalização e internalização. & $\begin{array}{l}\text { Zabot e Silva (2002); Amaral et al. (2006); Morgan e } \\
\text { Liker (2008); Gonçalves e Rodrigues (2008). }\end{array}$ \\
\hline $\begin{array}{l}\text { Mapas conceituais do conhecimento buscam } \\
\text { representar, graficamente, para facilitar sua } \\
\text { assimilação. }\end{array}$ & $\begin{array}{l}\text { Davenport e Prusak (1998); Terra (2001), Cañas et } \\
\text { al.(2003); Cañas et al.(2004). }\end{array}$ \\
\hline $\begin{array}{l}\text { Escopo do conhecimento e das habilidades da empresa } \\
\text { e critérios de avaliação. }\end{array}$ & Engel et al. (2000); Spender (2001). \\
\hline $\begin{array}{l}\text { Inovação contínua e desenvolvimento de projetos de } \\
\text { gestão do conhecimento. }\end{array}$ & Nonaka (2000); Johnson (2004). \\
\hline Conhecimento como informação valiosa. & $\begin{array}{c}\text { Nonaka e Takeuchi (1997); Davenport (2001); Zabot e } \\
\text { Silva (2002); Amaral et al. (2006); Morgan e Liker } \\
\text { (2008); Gonçalves e Rodrigues (2008). }\end{array}$ \\
\hline $\begin{array}{l}\text { Conhecimento recurso primário para indivíduos e } \\
\text { economia. }\end{array}$ & Drucker (2000). \\
\hline
\end{tabular}

Fonte: Elaborado pelos autores com base na literatura

\section{Metodologia}

\subsection{Caracterização do ambiente de pesquisa}

A pesquisa foi realizada em uma empresa de desenvolvimentos de sistemas ERP. Esta desenvolve e implementa um sistema de ERP com foco nas organizações dos setores de metalúrgica, moveleiras e distribuidoras. Ainda trabalha com um sistema para lojistas moveleiros, outros produtos desenvolvidos são para integração de notas fiscais eletrônicas com o governo, para gerenciar arquivos utilizados em ISO e sistema gerador de relatórios. O assunto da pesquisa foi na abordagem de toda a organização, com o objetivo de contextualizar as práticas de implementação de sistema e necessidades de melhorar o seu desempenho.

\subsection{Objetivos da pesquisa}

Este trabalho propõe um questionário, em forma de check list, para contribuir na análise de requerimentos da implementação do sistema ERP desenvolvido pela empresa do módulo de suprimentos, demonstrando como este pode ser útil para captar o conhecimento, procedimentos e processos existentes na empresa, facilitando e melhorando a implementação do sistema. Esta abordagem pretende apresentar a importância de captar esses conhecimentos e quanto impactante pode ser para a troca do sistema. No mesmo sentido descrever como são as fases de implementação e os impactos sofridos por uma análise de requerimento incompleto ou não totalmente definidos. Busca ainda, demonstrar as oportunidades que há com uma melhor investigação dos dados e 
processos da empresa e como este pode gerar vantagens não só para a empresa como para o implementador de sistema que precisa modelar o sistema para que melhor atenda o cliente.

\subsection{Técnicas e procedimentos adotados}

O trabalho foi realizado com base teórica destacados no item 2 deste artigo, de forma descritiva, que segundo Gil (1991), significa descrever as características de determinada população ou fenômeno ou o estabelecimento de relações entre variáveis. A abordagem desenvolvida apontará para o estudo de caso, que para Roesch (1999), possibilita o entendimento intensivo e detalhado acerca de um problema de pesquisa, uma vez que enfoca um número relativamente pequeno de casos ou um caso único seguindo-se alguns pressupostos na literatura.

Ainda sobre estudo de caso, Yin (2005) define que este pode ser utilizado em diversas situações, colaborando com o aprofundamento do conhecimento sobre fenômenos individuais. O autor destaca que um estudo de caso apresenta quatro etapas distintas: planejamento - fase em que o projeto de pesquisa é estruturado; coleta de dados - obtenção de evidências para o estudo; análise e interpretação dos dados - examinar, categorizar e classificar as informações coletadas; e relatório e apresentação dos resultados.

A pesquisa limitou-se somente ao módulo de suprimentos do sistema ERP adaptado a realidade da empresa a ser implementado, observando sua amplitude e abrangência no tocante do todo de uma implementação de um sistema ERP. Assim, analisando todas as etapas e processos que envolvem as necessidades da empresa para a troca de sistema e a abrangência de suas atividades, que por muitas vezes não analisadas adequadamente comprometem na implementação e troca do programa, também nas atividades da empresa pós-virada de sistema.

Os dados coletados para criação da proposta tiveram as seguintes fontes:

- Metodologia do projeto de implementação do sistema ERP (adaptado do PMI);

- Documentos de análise de requerimentos;

- Avaliações de projetos;

- Solicitações de customização;

- Projetos cadastrados no portal de gerenciamento de projetos WP Professional.

Nos dados coletados buscou-se observar as etapas que impactaram na implementação do sistema ERP da empresa deste estudo de caso, de maneira que o sistema não contempla ou necessita de customização. Ainda foi observado tempo de projeto previsto e tempo necessário de investimento por parte da empresa que desenvolve e implementa o sistema para ajustar tarefas ou processos nos clientes contratantes do ERP. 


\section{Desenvolvimento da pesquisa}

\subsection{Conhecendo a situação atual do cliente para implementação do sistema}

A organização que contrata o sistema ERP desta empresa compra módulos do ERP divididos em: Comercial, Suprimentos, Manufatura, Administrativo, Financeiro e Custos. De certa maneira busca atender as necessidades do seu negócio, visando gerar automação, vantagens competitivas, agilidade nos seus processos e entre outros. Mediante análise, todos estes módulos contemplam as atividades de uma empresa. Porém como o sistema é feito para diversos nichos de mercado, nem todo módulo atende completamente as atividades da organização ou seus processos. Cada negócio possui seus produtos, cada qual com seus processos específicos.

$\mathrm{Na}$ coleta de dados identifica-se que empresas no mesmo setor com produtos similares, concorrentes deste mercado possuem atividades, tarefas e processos diferenciados. O resultado disto é que o sistema passa a não contemplar todas as necessidades da organização, sendo necessária que o sistema oferecido pela fornecedora do sistema seja customizado a necessidade do cliente.

As customizações ocorrem de diversas maneiras, podendo ser no desenvolvimento de relatórios criados a partir de dados e informações já existentes no ERP ou ainda criando módulos específicos para o cliente, um exemplo evidenciado é o de comissões do comercial, dificilmente a maneira de pagar as comissões é igual entre as empresas, cada qual possui suas particularidades.

Essas peculiaridades devem ser detectadas na fase de Análise de Requerimentos do projeto, nesta etapa é que o implementador de sistema observa estas necessidades, modelando sua parametrização e implementação, porém esta situação não possui procedimentos uniformes. Cada qual investiga e questiona o cliente de acordo com o seu conhecimento, não há nenhuma ferramenta definitiva, consolidada e de uso geral para analisar se o sistema vai contemplar as atividades e processos do cliente. Como não existe uma ferramenta ou pesquisa para a fase de análise de requerimentos de fato o projeto do ERP é afetado por diversos motivos como: modelagem do sistema ao negócio do cliente inadequada, relatórios e módulos inexistentes para atender a carência do cliente e principalmente para a troca de sistema. As necessidades não detectadas também fazem que os custos do projeto aumentem tanto para a empresa que contratou o sistema como para quem desenvolve o mesmo.

\subsection{Identificação das fases de implementação do projeto de ERP}

Dentro deste estudo de caso, observa-se que as principais fases do projeto são divididas em:

- Abertura do projeto: aqui é apresentada a empresa que irá implementar o sistema, o canal de comunicação existente com a organização. É prestado o escopo do projeto nos módulos de gestão comercial, suprimentos, manufatura, financeira e administrativa. São feitas as descrições do 
projeto, premissas e objetivos a serem respeitados. Também são demonstrados os impactos e as restrições que o projeto causará na organização que está contratando o sistema. Nesta fase do projeto é demonstrada a metodologia e as ferramentas que serão utilizadas para implementação do sistema, os integrantes e os gerentes de projeto e suas atribuições;

- Análise de requerimentos: Esta fase é uma das mais importantes no projeto, porque é a partir dela que serão definidos como será feito o treinamento e como ficará a modelagem e parametrização do sistema para atender as necessidades do cliente. Nesta etapa deve ser feito toda a investigação e questionamento referente ao módulo a ser implantado, são analisados todos os processos realizados nos setores que sofrerão o impacto da implantação. Aqui que devem ser vistos o que as atividades do cliente irão utilizar no sistema, verificando se o sistema irá atender em todos os quesitos as especificações do cliente. As necessidades podem ser alguns campos específicos nas telas de programas, relatórios, consultas, informações gerenciais ou até novos módulos inteiros, declarando assim situações que o sistema não contempla ou necessite de customização.Se esta fase obtiver poucas informações, as próximas etapas do projeto podem não obter sucesso mediante inadequados parâmetros, treinamentos e modelagem dos módulos para com a realidade do cliente. Os problemas gerados nesse momento podem fazer com que todas as próximas fases tenham impactos como atrasos de cronograma e custos não previstos. Esta fase deve ser o limite para serem vistos situações que o sistema não contempla e solicitar customizações;

- Treinamento: Os treinamentos são realizados com os usuários chaves e nesta fase é apresentado ao cliente tudo que o sistema possui e o que ele faz. Neste momento ainda não há disponíveis as customizações que o cliente necessita para adaptar o sistema a necessidade da empresa, o intuito é treinar ao cliente em tudo o que seu módulo possui e fazer com que a organização use ao máximo todas as funções. Os treinamentos são feitos com cadastros reais que a empresa possui visando sempre mostrar as funcionalidades que o sistema pode proporcionar. Ainda são utilizados manuais do sistema, data-show e dinâmicas de treinamento. A partir deste ponto são acionadas forças de tarefa para cadastros que influenciam no funcionamento do sistema, estes cadastros podem ser: cadastros de itens, fornecedores, clientes, representantes, entre outros;

- Adequação dos processos: Todas as tarefas, atividades e processos que são feitas pela empresa nesta fase serão adequados ao ERP desenvolvido. As pessoas que irão utilizar o programa serão envolvidas para que a partir desta etapa façam as suas atividades dentro do ERP em caráter de simulação e testes. Ainda neste momento, já estão disponíveis todas as customizações geradas pela análise de requerimentos. Sendo assim todos os processos que a empresa executa hoje com o sistema legado deve ser feito com o ERP. Neste ponto é visualizado o funcionamento do novo sistema, caso existam situações que o mesmo ainda não contemple, elas serão detectadas novamente aqui, verificando-se a falha na análise de requerimentos; 
- Validação dos dados: Esta parte preocupa-se com as respostas que o sistema irá dar a todos os processos da empresa, são inseridos dados reais a fim de detectar falhas que interrompam os processos da empresa. Esta etapa passa a ser mais complexa que a anterior, pois antes de executar as tarefas necessárias que a empresa precisa, necessita-se de total exatidão nos dados gerados pelo sistema. Além do citado são validados todos os dados que foram cadastrados no sistema após a fase de treinamentos. Qualquer resultado negativo pode ser atribuído novamente a análise de requerimentos ao qual não previu os tratamentos adequados;

- Piloto: Nesta fase é reservado um dia para que toda a empresa utilize o novo sistema, como se estivesse em produção, executar todas as operações necessárias a fim validar a utilização do novo sistema. Este momento é a última chance para sinalizar se o sistema irá ou não ser trocado, para ver também se o programa irá dar resposta adequada a todas as necessidades da empresa. É verificada ainda a segurança dos usuários em utilizar este novo sistema e a capacidade deles em solucionar problemas da empresa com o mesmo. A falta de sucesso do piloto do sistema também é atribuída à análise de requerimentos a qual não previu todos os programas necessários para a troca do sistema;

- Virada do sistema: Nesta etapa do projeto a empresa já inicia a utilização do novo sistema, nesta fase todos os envolvidos pela utilização do sistema são responsáveis pela inserção dos dados para fazer com que toda a empresa não tenha que comprometer com paradas seus processos devido a informações incorretas. Neste momento já não deve aparecer nenhuma surpresa referente ao sistema, pois a sua virada é positivada a partir do resultado do piloto que foi rodado anteriormente, mas conforme constatado nos dados coletados, não é a realidade de todas as viradas de sistema.

Abaixo, descreve-se em forma de fluxograma o exposto acima: 


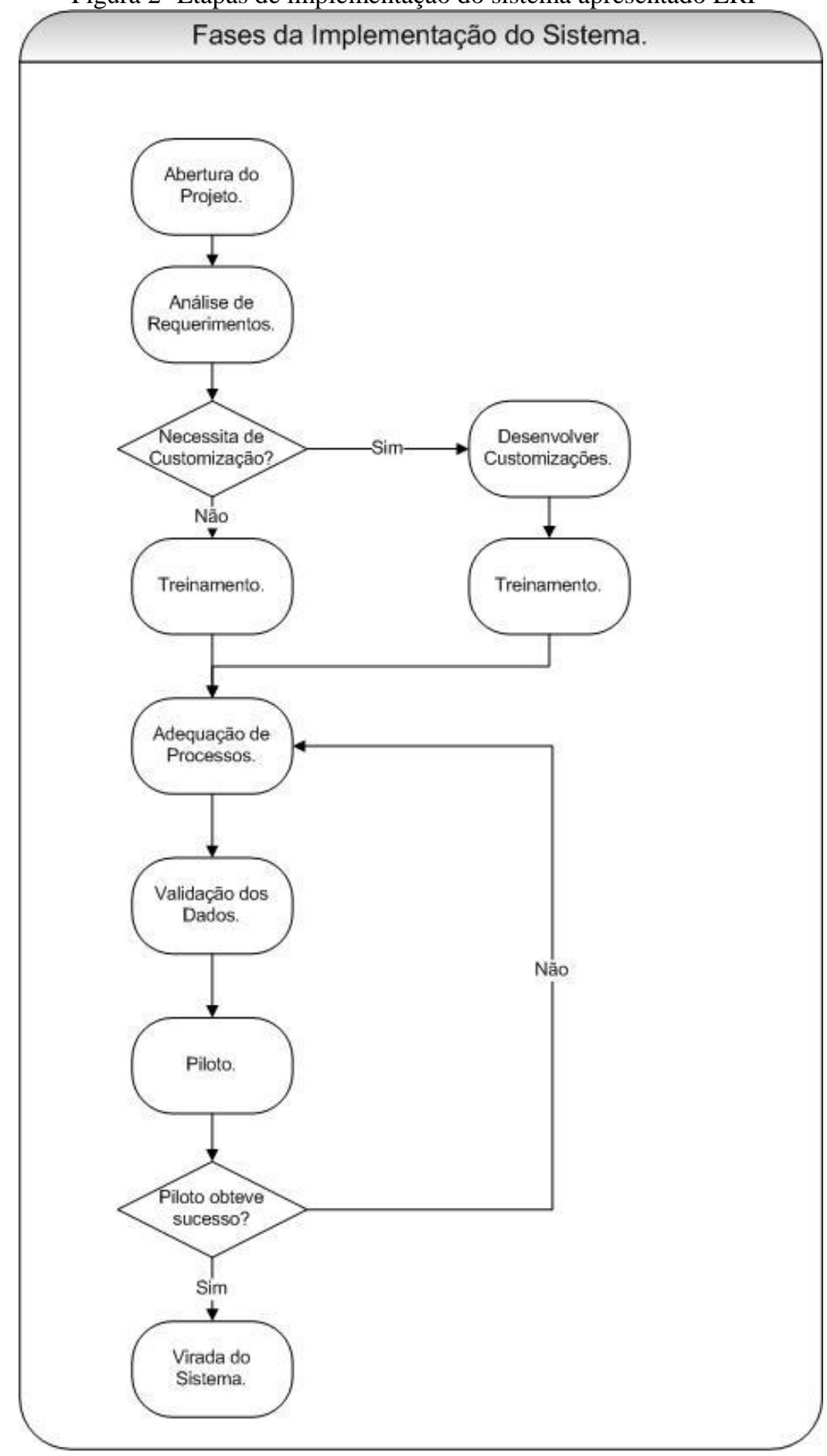

Fonte: Empresa pesquisada pelo aluno

\subsection{Situação proposta: questionário para análise de requerimentos do módulo de suprimentos}

A fase de análise de requerimentos fica condicionada ao conhecimento que o implementador possui sobre a área de suprimentos, com maior conhecimento menos chance de erros para as próximas fases ficarão em aberto, quanto menor o conhecimento mais oportunidades de problemas serem ocasionados por esta fase. O mesmo ocorre do lado do cliente, quanto mais este conseguir explicitar o conhecimento existente sobre os processos da empresa menor é a chance de problemas 
para as etapas seguintes.

Sugere-se um questionário com todas as situações em que o módulo de suprimentos do sistema ERP disponibiliza determinadas funções, o check list proposto ainda tenta aproximar as atividades da empresa com questões que determinem o limite do que pode ser feito com o sistema e do que a empresa necessita fazer ou alcançar. A sugestão ainda quer fazer com que qualquer implementador, não importando o seu grau de conhecimento ou do cliente, capte todas as informações necessárias para parametrizar e modelar o programa, verificando todos os pontos que o sistema não contempla e que sejam necessárias customizações. O módulo de suprimentos é subdividido em: Fornecedores, Solicitação de Compra, Cotação de Compra, Contratos de Fornecedores, Pedido de Compra, Aviso e Bloqueio de Recebimento, Recebimento, Estoque, Avaliação de Fornecedores, EDI, Alçada de Valores e Inspeção de Recebimento.

Quadro 2 - Questões para levantamento dos dados de fornecedores e solicitação de compra

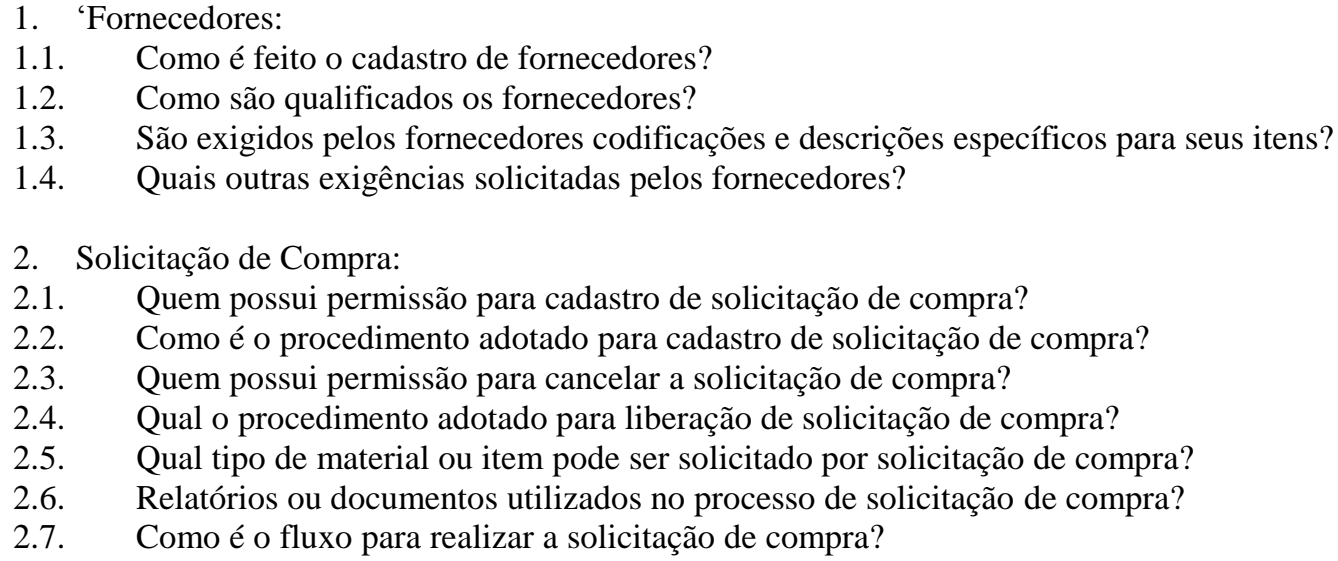

Figura 3- Fluxo de solicitação de compra

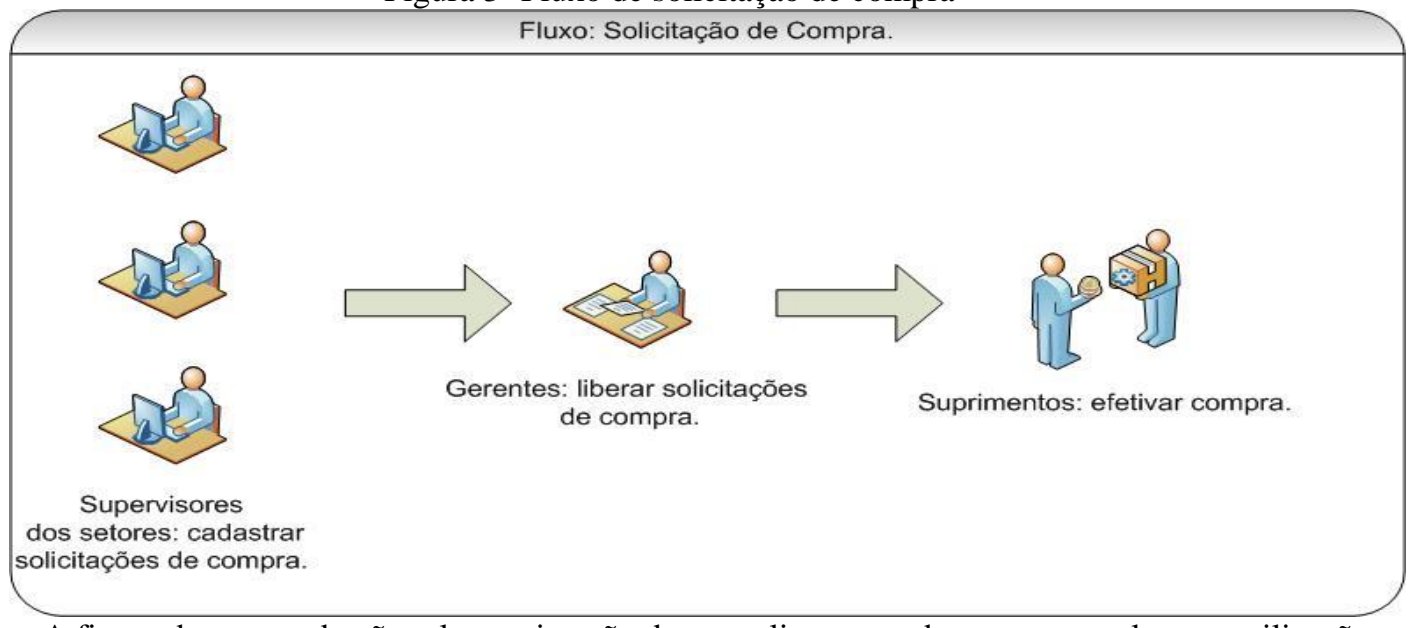

Obs.: A figura demonstrada não relata a situação de seus clientes sendo mero exemplo para utilização. Fonte: Autores deste artigo - empresa pesquisada no estudo de caso 
Quadro 3- Questões para levantamendo dos dados de cotação de compra

\begin{tabular}{|c|c|}
\hline & ação de Compra: \\
\hline 3.1 . & Qual o procedimento adotado para cadastro de cotação de compra? \\
\hline 3.2 . & Como são enviadas as cotações de compra? \\
\hline 3.3 . & Quantos fornecedores são necessários para consolidar a cotação de compra? \\
\hline 3.4 . & Qual o procedimento adotado para análise de cotação de compra? \\
\hline 3.5 . & Qual o procedimento adotado para liberação de cotação de compra? \\
\hline 3.6 . & Relatórios ou documentos utilizados no processo de cotação de compra? \\
\hline 3.7. & Como é o fluxo para realizar a cotação de compra? \\
\hline
\end{tabular}

Figura 4 - Fluxo de cotação de compra

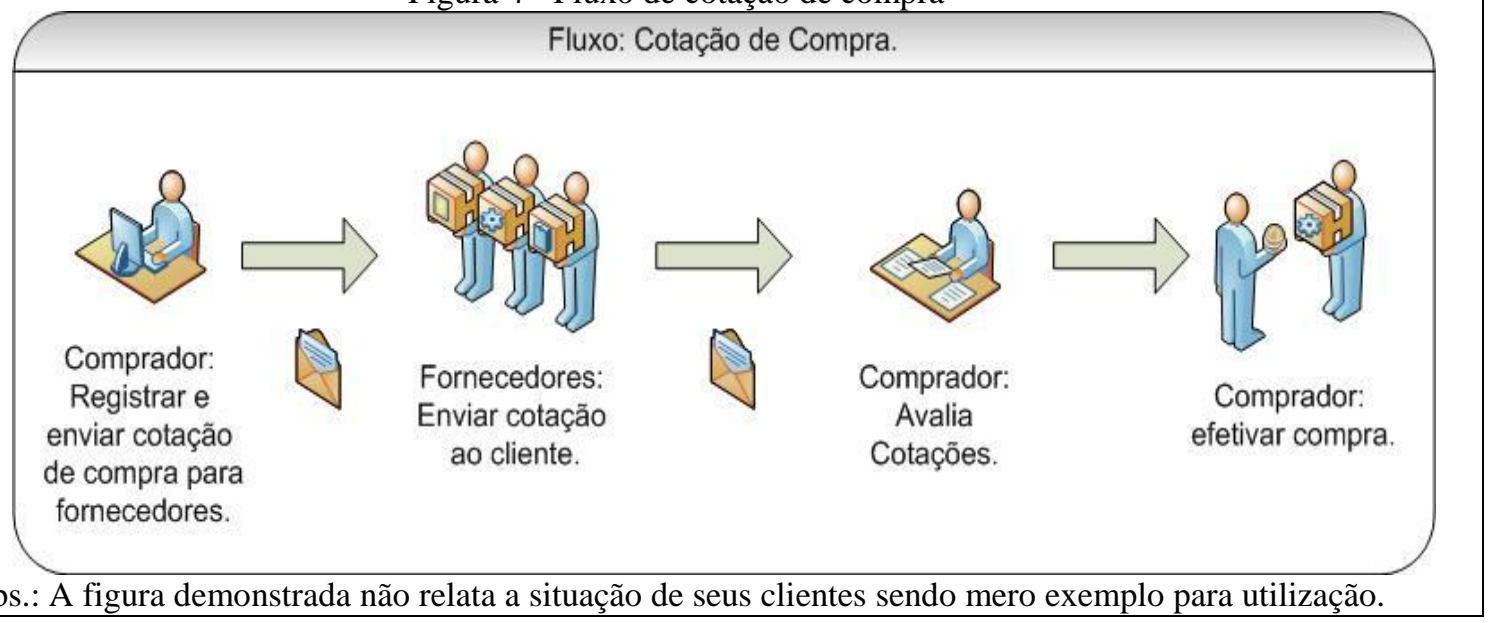

Fonte: Autores deste artigo - Empresa pesquisa neste estudo de caso

Quadro 4 - Questões para levantamendo dos dados de contratos de fornecedores e pedido de compras

4. Contratos de Fornecedores:

4.1. Qual o procedimento adotado para cadastrar um contrato com um fornecedor?

4.2. As políticas de contratos com fornecedores é por cotas de valores, itens ou outros?

4.3. Como é auditada a utilização dos contratos?

4.4. Qual o procedimento adotado para renovar ou modificar um contrato com um fornecedor?

4.5. Relatórios ou documentos utilizados nos contratos de fornecedores?

5. Pedidos de Compra:

5.1. Qual o procedimento adotado para cadastro de pedido de compra?

5.2. Qual o procedimento adotado para cadastro de pedido de compra de serviço?

5.3. Qual o procedimento adotado para cadastro de pedido de compra de frete?

5.4. Qual o procedimento adotado para cadastro de pedido de compra a partir de solicitação de compra?

5.5. Qual o procedimento adotado para cancelamento de cedido de compra?

5.6. É utilizado fornecedores preferenciais para itens?

5.7. É utilizado informar centro de custo ou conta contábil no pedido de compra?

5.8. Quem possui permissão para cadastrar pedidos de compra?

5.9. Como são enviados os pedidos de compra para os fornecedores?

5.10. Qual o procedimento adotado para liberação de ordens de compra planejadas (MRP)?

5.11. Quais as consultas utilizadas em pedido de compra?

5.12. Relatórios ou documentos utilizados em pedido de compra?

5.13. As compras são centralizadas na matriz ou cada unidade realiza as suas compras?

5.14. É utilizado tabela de preço de compra por fornecedor?

5.15. Como é o fluxo para realizar o pedido de compra?

5.16. Outras considerações que devem ser feitas sobre pedido de compras? 


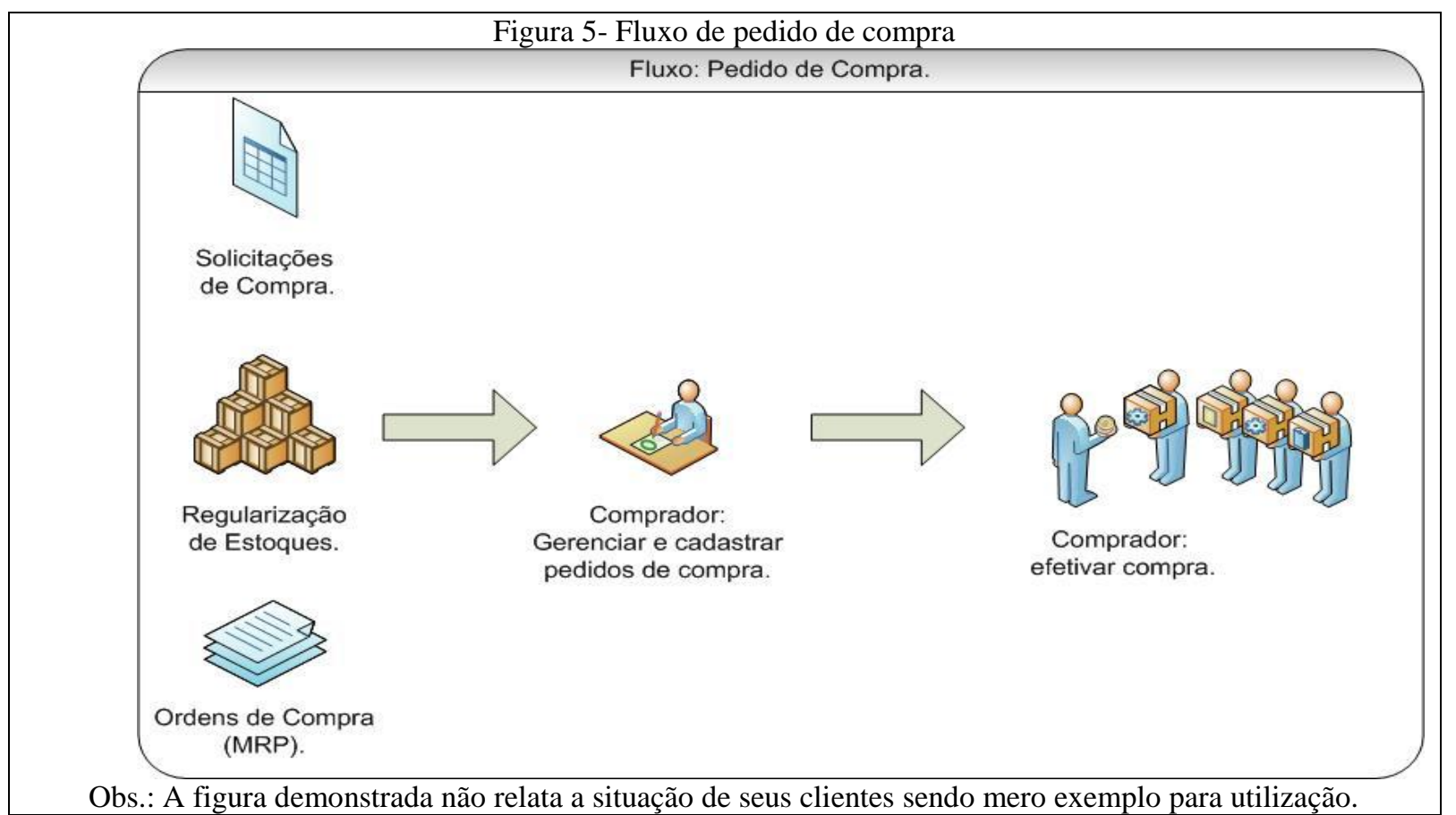

Fonte: Autores deste artigo - Empresa pesquisaneste estudo de caso

Quadro 5 - Questões para levantamento dos dados de aviso e bloqueio de recebimento e recebimento

6. Aviso e Bloqueio de Recebimento:

6.1. Qual o procedimento adotado para cadastro de aviso e bloqueio de recebimento?

6.2. Qual o procedimento adotado para desbloqueio de aviso de recebimento?

6.3. Relatórios ou documentos utilizados em aviso e bloqueio de recebimento?

6.4. É utilizado relatório de histórico de divergências de aviso e bloqueio de recebimento?

6.5. Como é o fluxo para realizar o aviso e bloqueio de recebimento?

7. Recebimento:

7.1. Qual o procedimento adotado para manutenção de nota fiscal de entrada?

7.2. Qual o procedimento adotado para conferência de nota fiscal de entrada?

7.3. Quais as consultas utilizadas no módulo de recebimento de nota fiscal de entrada?

7.4. Relatórios ou documentos utilizados em pedido de compra?

7.5. É utilizado emissão de etiquetas na entrada de notas fiscais de entrada?

7.6. Quais os layouts e modelos de etiquetas são utilizados?

7.7. Quais os modelos e fabricantes das impressoras que emitem estas etiquetas?

7.8. É utilizado código de barras nas etiquetas? Qual o padrão do código de barras?

7.9. As notas fiscais de entrada exigem um pedido de compra cadastrado anteriormente?

7.10. É realizado consistência do valor dos itens na nota fiscal de entrada com a tabela de preço de compra?

7.11. É enviado e-mail ou notificação de qualquer tipo para quando efetuado cadastro de nota físcal de entrada?

7.12. Como é o fluxo para realizar a inclusão de notas fiscais de entrada? 


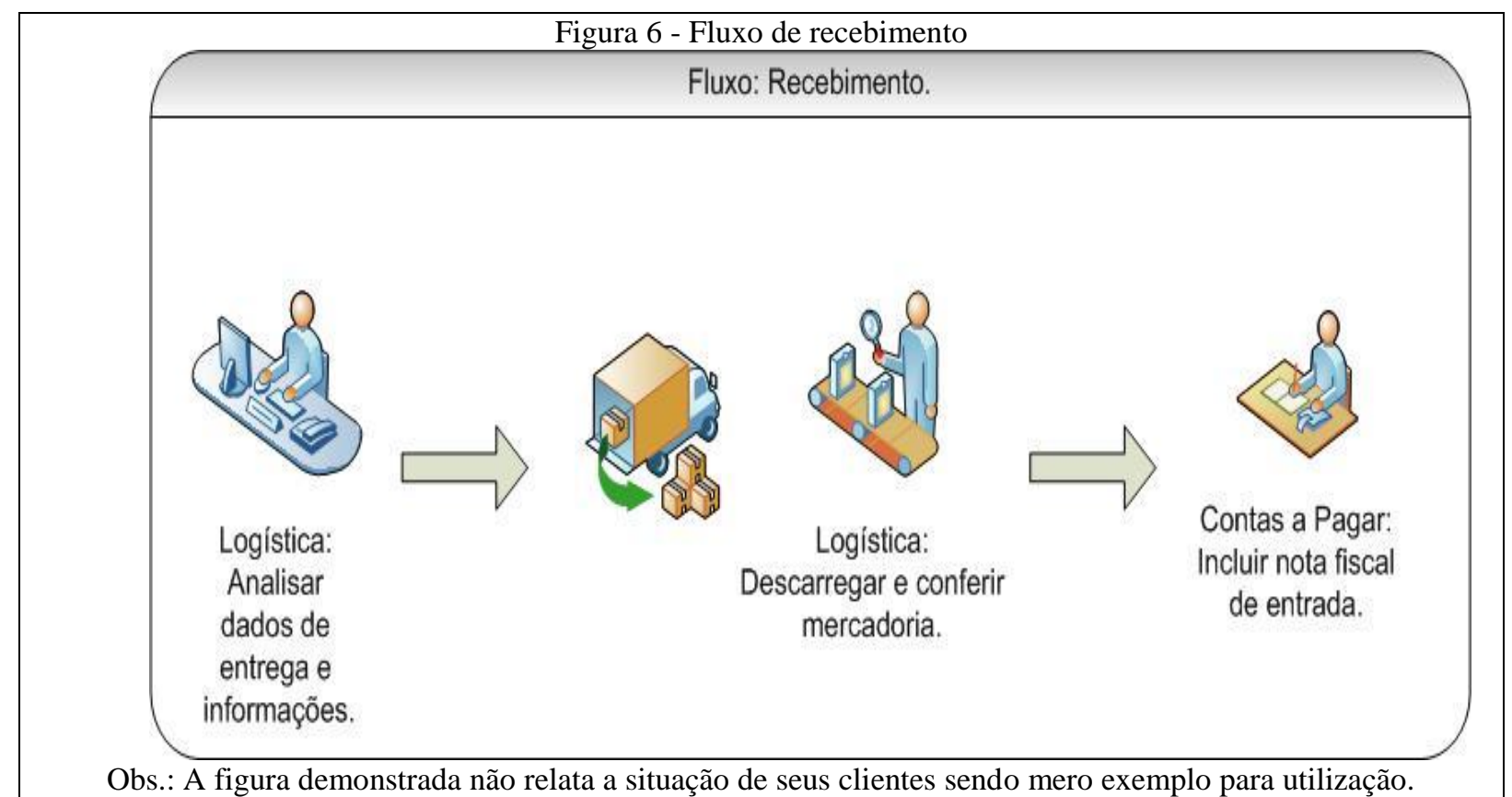

Fonte: Autor deste artigo - Empresa pesquisada pelo aluno

Quadro 6 - Questões para levantamendo dos dados de estoques
8. Estoques:
8.1. Qual o procedimento adotado para realizar movimentações planejadas de estoque?
8.2. Como é feito a requisição de itens do estoque?
8.3. A requisição de itens do estoque utiliza código de barras e leitores de códigos de barras?
8.4. Como é feita a entrega de itens no estoque?
8.5. A entrega de itens no estoque utiliza código de barras e leitores de códigos de barras?
8.6. Qual o procedimento adotado para realizar movimentações não planejadas de estoque?
8.7. Como é feito a requisição não planejada de itens do estoque?
8.8. A requisição não planejada de itens do estoque utiliza código de barras e leitores de códigos de barras?
8.9. Como é feita a entrega não planejada de itens no estoque?
8.10. A entrega não planejada de itens no estoque utiliza código de barras e leitores de códigos de barras?
8.11. Como é feito a implantação de estoques?
8.12. Qual o procedimento utilizado para devolução de itens no estoque?
8.13. Qual o procedimento utilizado para realizar a transferência de itens entre estoques?
8.14. Qual o procedimento utilizado para realizar acerto dos estoques?
8.15. É utilizado lotes no estoque?
8.16. É utilizado transferência de estoques ente empresas do mesmo grupo? Qual o procedimento utilizado para realizar a transferência de estoques entre empresas do mesmo grupo?
8.17. Qual o procedimento utilizado para contagem cíclica dos itens no estoque?
8.18. É utilizado localização de itens no estoque? Qual o procedimento utilizado para rastrear os itens em estoque na empresa?
8.19. É utilizado padrões de conversão de unidade de medida do item?
8.20. Quais as consultas utilizadas em estoques?
8.21. Relatórios ou documentos utilizados em estoques?
8.22. Como é o fluxo para realizar a movimentação de estoque? 


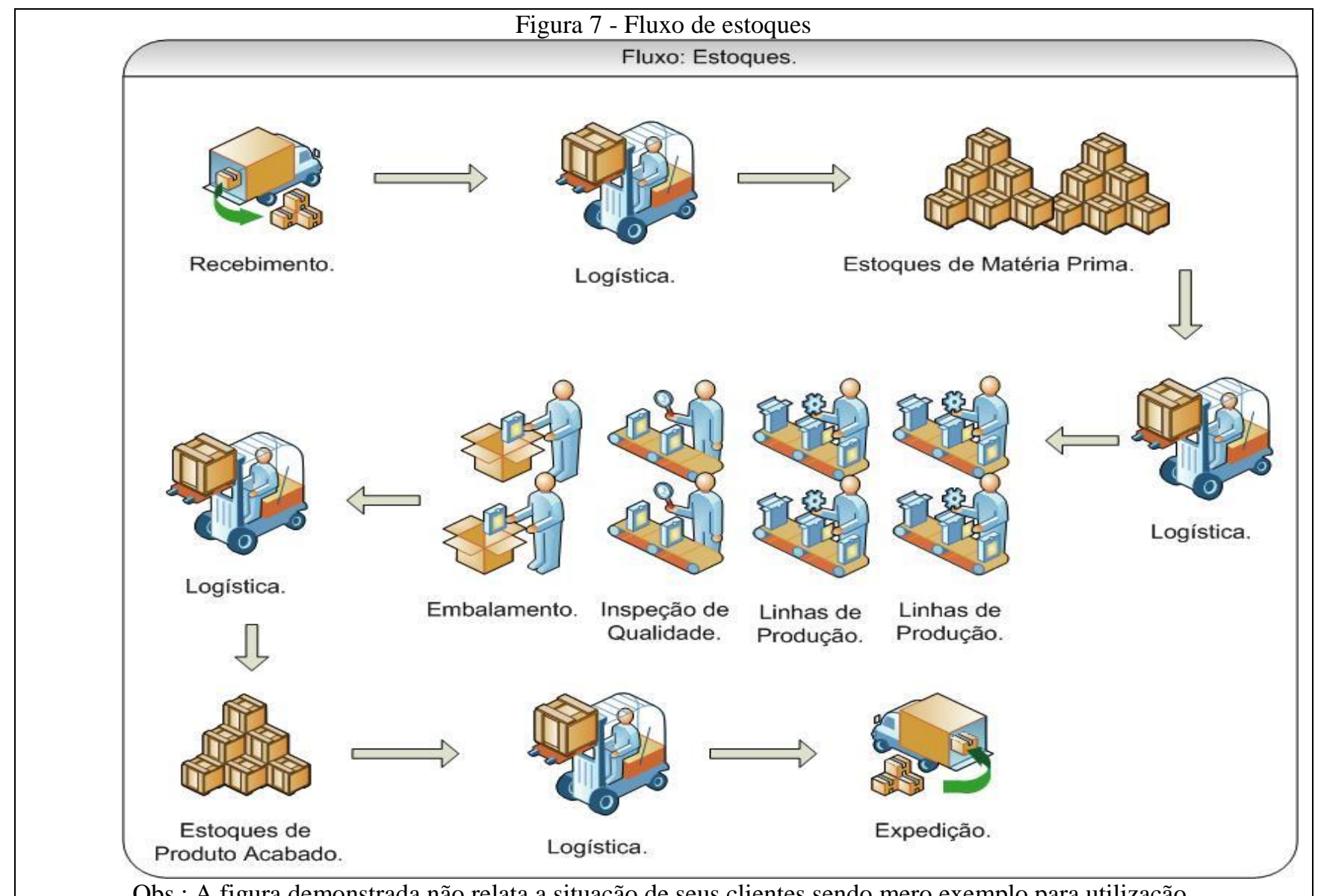

Fonte: Autores deste artigo - Empresa pesquisaneste estudo de caso

Quadro 7- Questões para levantamento dos dados de avaliação de fornecedor, EDI, alçada de valores e inspeção de recebimento

9. Avaliação de Fornecedor:

9.1. Qual o procedimento adotado para avaliação dos fornecedores?

9.2. Como é determinado os aspectos de avaliação para cada fornecedor?

9.3. O índice de qualificação de fornecedor é gerada por período ou por atividade?

9.4. Qual o procedimento adotado para calculo da nota da qualificação do fornecedor?

9.5. Qual o procedimento adotado para informar o fornecedor do seu índice de qualificação?

9.6. Quais as consultas utilizadas em Avaliação de Fornecedores?

9.7. Relatórios ou Documentos utilizados em Avaliação de Fornecedores?

10. EDI (Transferência Eletrônica de Dados):

10.1. Quais fornecedores utilizam EDI?

10.2. Que tipo de informação é processada pelo EDI?

10.3. Quais os formatos de arquivos são utilizados para EDI?

10.4. Qual o procedimento para importação e exportação dos dados de EDI?

10.5. Quais as consultas utilizadas em EDI?

10.6. Relatórios ou Documentos utilizados em EDI?

11. Alçada de Valores:

11.1. Como é definida a política de alçada de valores para compras?

11.2. Como é definida a hierarquia de alçada de valores?

11.3. A alçada de valores possui cotas por centros de custos?

11.4. Cada comprador possui cotas por centros de custos ou a cota é para todo o setor de compras?

11.5. Quando ultrapassada a cota de valores qual o procedimento adotado para bloqueio e liberação da compra?

11.6. Quais as consultas utilizadas em Alçada de Valores?

11.7. Relatórios ou Documentos utilizados em Alçada de Valores?

11.8. Como é o fluxo para realizar a alçada de valores? 
12. Inspeção de Recebimento:

12.1. Quais fornecedores recebem inspeção de recebimento?

12.2. Quais itens ou produtos são feitos inspeção de recebimento?

12.3. Qual o procedimento adotado para inspeção de recebimento?

12.4. Quais os roteiros utilizados para inspeção de recebimento?

12.5. Qual o procedimento para efetuar manutenção e apontamento da inspeção de recebimento?

12.6. Qual o procedimento adotado para geração de ocorrências de inspeção de recebimento?

12.7. Quais as consultas utilizadas em Inspeção de Recebimento?

12.8. Relatórios ou Documentos utilizados em Inspeção de Recebimento?

12.9. Como é o fluxo para realizar a inspeção de recebimento?

Fonte: Autores deste artigo - Empresa pesquisaneste estudo de caso

\section{Análise e interpretação dos resultados}

O objetivo proposto com este trabalho é que com a utilização deste check list seja possível minimizar problemas provenientes de uma análise de requerimentos com poucas informações sobre os clientes que desejam implementar um sistema. A riqueza destas informações se deve basicamente ao conhecimento do implementador do módulo, quanto maior o conhecimento melhor será parametrizado e modelado o sistema, mais fácil também fica de reconhecer tarefas, atividades e processos que este desenvolvimento não contempla e possa ser customizado.

Outro resultado que se deseja com este estudo é fazer com que todo conhecimento tácito existente na empresa, fiquem explícito para ser armazenado no sistema. Tornando-se um grande diferencial para a empresa que esta adquirindo o software, confiar seus processos em um sistema que absorveu suas operações de maneira a ser traduzido e interpretado por este. Descentralizando e disseminando o conhecimento de forma a ser utilizado por todos.

Aumentar a eficiência dos projetos é outro resultado projetado por esta proposta, o questionário quer fazer com que o máximo de informações seja captado para que todas as ações sejam providenciadas para não impactarem no cronograma e nos custos do projeto. A análise de requerimentos seguindo esta sugestão irá fazer com que muitas atividades não contempladas sejam previamente customizadas com informações mais apuradas dos processos do cliente.

Esse artigo ainda tem o intuito de fazer com que não somente esta etapa de análise de requerimentos seja otimizada, mas a partir dos resultados da utilização desta proposta verificar as outras fases do projeto que podem sofrer melhorias e serem detalhadas a ponto de detectar novos meios de tornarem os projetos mais efetivos e eficientes.

\section{Considerações finais}

A possibilidade de melhorias em etapas de projetos de implementação do sistema estudado, é o reflexo que a empresa já está com certo nível de maturidade na gestão de seus projetos. A proposta deste check list para análise de requerimentos é uma resposta a lacuna existente entre o software e a necessidade das empresas. A utilização deste estudo vê ganhos significativos ao 
trabalho de implementação do sistema, colocando a disposição uma série de perguntas que facilitam à detecção de várias situações inerentes a etapa aqui desenvolvida.

Os benefícios desta sugestão visualizam um avanço na detecção das situações onde o sistema deve atender as necessidades do cliente, pois a partir dele o implementador pode vislumbrar as várias situações que o cliente necessita do diferencial deste para suas operações. Outros benefícios que já foram citados neste estudo é a obediência do projeto ao cronograma de atividades, por consequiência o respeito ao custo do projeto. A riqueza de informações da análise de requerimentos pode atuar como um aliado ao implementador a partir de sua utilização para detectar situações que este software não contempla, fazendo com que o próprio sistema possa evoluir com as novas alterações que sejam adaptadas para o cliente.

As dificuldades que esta proposta possa vir a enfrentar que identificam alguns passos limitadores enfatizam o tempo de implantação do sistema, o que pode fazer com que a etapa de análise de requerimentos não tenha um período necessário para que seja possível captar todas as informações. Outra dificuldade que pode limitar o desenvolvimento do estudo é a falta de responsáveis ou conhecedores dos processos da empresa, ou seja, a rotatividade de funcionários do setor. Outro aspecto a ser enfrentado pode ser o custo das possíveis customizações do sistema, cada atividade que este desenvolvimento não contempla deve ser customizada, porém este custo é repassado ao cliente que por sua vez pode não querer absorver sozinho os custos.

Desde já, a análise realizada neste artigo pretende se tornar um aliado ao implementador do sistema estudado para que nas implementações consiga obter o máximo de informações dos processos do cliente. Fazendo com que os projetos sejam agilmente executados com um maior grau de informações sobre o módulo sugerido no estudo. Também enriquecendo a investigação aos olhos do cliente mostrando um trabalho previamente tabulado e organizado para a execução da tarefa de analisar os requerimentos para um ERP.

\begin{abstract}
The central goal of this work is to propose a suggestion applied the requirements analysis phase of the project of implementation of an ERP system for the supply module. The success of requirements analysis step impacts in all subsequent project, working mainly in project timelines and costs. The challenge is to make this system implementers can with this check list to discover all the activities, tasks and processes existing in the area of supply and logistics companies. To do this was conducted a case study in an enterprise business management systems, analyzing data from various sources about their projects and verifying which topics main adjustments and investments projects. Are shown which project phases of implementation of such a system and its flow. The proposed questionnaire is done according to the subdivisions of supply module to get the most out of enterprise information system that will change. At the end of work sets out the results you want with the proposal.
\end{abstract}

Keywords: requirements analysis; system; supplies. 


\section{Referências}

AMARAL, D. C. et al. Gestão de desenvolvimento de produtos: uma referência para a melhoria do processo. São Paulo: Saraiva, 2006.

ANTUNES, M. T. P.; MARTINS, E. Capital intelectual: verdades e mitos. Revista de Contabilidade \& Finanças da USP. São Paulo: ano XIII, nº 29, p.41-54, mai/agos.2002.

CAÑAS, A. J. et al. A summary of literature pertaining to the use of concept mapping techniques and technologies for education and performance support. The Institute for Human and Machine Cognition. Pensacola, Florida, 2003. Disponível em: 〈http://cmap.ihmc.us/Publications/>. Acesso em: 11 jul. 2010.

Cmaptools: A knowledge modeling and sharing environment. Pamplona, Spain, 2004. Disponível em: <http://cmc.ihmc.us/papers/cmc2004-283.pdf>. Acesso em: 11 jul. 2010.

CHOO, C. W. A organização do conhecimento. São Paulo: SENAC, 2003.

DAVENPORT, T. H. Ecologia da informação: porque só a tecnologia não basta na era da informação. 3. Ed. São Paulo: Futura, 2001.

DAVENPORT, T. H.; PRUSAK, L. Conhecimento empresarial: como as organizações gerenciam o seu capital intelectual. 7. ed. Rio de Janeiro: Campus, 1998.

DRUCKER, P. F. Aprendizado organizacional: gestão de pessoas para a inovação contínua. 1. Ed. Rio de Janeiro: Ed. Campus Ltda, 2000.

FURASTÉ, Pedro Augusto. Normas técnicas: para trabalho científico, elaboração e formatação. 14. Ed. Porto Alegre: Brasul Ltda, 2010.

GIL, Antonio Carlos. Como elaborar projetos de pesquisa. São Paulo: Atlas. 1991.

GONÇALVES, F. B.; RODRIGUES, M. V. R. Conectividade: uma dimensão para o aprendizado organizacional. In. ENEGEP-ENCONTRO NACIONAL DE ENGENHARIA DE PRODUÇÃO, XXVIII, 2008, Rio de Janeiro. Anais... Rio de Janeiro, ABEPRO, 2008.

HOLANDA, L. M. C.; CARVALHO, H. G. de; KOVALESKI, J. L. A percepção dos mestrandos em engenharia de produção da Universidade Tecnológica Federal do Paraná (UTFPR) - Campus Ponta Grossa, sobre a existência de ambientes de conhecimento. In. ENEGEP-ENCONTRO NACIONAL DE ENGENHARIA DE PRODUÇÃO, XXVIII, 2008, Rio de Janeiro. Anais... Rio de Janeiro, 2008.

JOHNSON, L. K. Como disseminar as melhores práticas. Harvard Management Update. HSM Management Update, n. 12, p. 15. In. HSM Management, v. 3, n. 44, maio/jun. 2004.

MORGAN, J. M.; LIKER, J. K. Sistema toyota de desenvolvimento de produto: integrando pessoas, processo e tecnologia. Porto Alegre: Bookman, 2008.

NONAKA, I. Aprendizado organizacional: gestão de pessoas para a inovação contínua. 1. Ed. Rio de Janeiro: Ed. Campus Ltda, 2000.

NONAKA, I.; TAKEUCHI, I. Criação de conhecimento na empresa: como as empresas japonesas geram a dinâmica da inovação. 9. Ed. Rio de Janeiro: Ed. Campus Ltda, 1997.

ROESCH, S. M. A. Projetos de estágio do curso de administração: guia para pesquisa, projetos, estágio e trabalhos de conclusão de curso. São Paulo: Atlas, 1999.

SPENDER, J. C. Gestão estratégica do conhecimento: integrando aprendizagem, conhecimento e competências. 1. Ed. São Paulo: Atlas S.A., 2001.

STEWART, T. A. Capital intelectual: a nova vantagem competitiva das empresas. Tradução de Ana Beatriz Rodrigues, Priscila Martins Celeste. $4^{\mathrm{a}}$. ed. Rio de janeiro: Campus, 1998. 
TERRA, J. C. C. Gestão do conhecimento: o grande desafio empresarial: uma abordagem baseada no aprendizado e na criatividade. 3. ed. são paulo: Negócio, 2001.

YIN, R. K. Estudo de caso: planejamento e métodos. 3. ed. Porto Alegre: Bookman, 2005.

ZABOT, J. B. M.; SILVA, L. C. M. da. Gestão do conhecimento: aprendizagem e tecnologia construindo a inteligência coletiva. São Paulo: Atlas, 2002.

\section{Dados dos autores:}

Nome completo: Zaida Cristiane dos Reis

Filiação institucional: Universidade de Caxias do Sul

Departamento: Engenharia Ambiental

Função ou cargo ocupado: Professora Titular

Endereço para correspondência (bairro, cidade, estado, país e CEP): Rua Francisco Getúlio Vargas,

1130 - Bloco F, Bairro Petrópolis, Caxias do Sul (RS), Brasil, CEP 92020-972.

Telefones para contato: (42) 32182100

e-mail: zcreis@gmail.com

Nome completo: Tiago da Rosa

Filiação institucional: Universidade de Caxias do Sul

Departamento:

Função ou cargo ocupado:

Endereço para correspondência (bairro, cidade, estado, país e CEP): Rua Francisco Getúlio Vargas,

1130 - Bloco F, Bairro Petrópolis, Caxias do Sul (RS), Brasil, CEP 92020-972.

Telefones para contato: (42) 32182100

e-mail: tiago.rosa@focco.com.br

Nome completo: Gabriel Sperandio Milan

Filiação institucional: Universidade de Caxias do Sul

Departamento: Administração

Função ou cargo ocupado: Professor Visitante

Endereço para correspondência (bairro, cidade, estado, país e CEP): Rua Francisco Getúlio Vargas, 1130 - Bloco F, Bairro Petrópolis, Caxias do Sul (RS), Brasil, CEP 92020-972.

Telefones para contato: (42) 32182100

e-mail: gabmilan@terra.com.br 